\title{
DEVELOPMENT OF SOLAR PANELS TRACKER SENSOR
}

\author{
Andrejs Snegovs, Henriks Putans, Liene Kancevica, Imants Ziemelis \\ Latvia University of Life Sciences and Technologies, Latvia \\ andrejs.snegovs@gmail.com, henriksooo@inbox.lv, liene.kancevica@llu.lv, imants.ziemelis@1lu.lv
}

\begin{abstract}
The aim of the study is to develop a sensor for solar panels tracking devise, using infrared diodes. Regardless of the relatively low intensity of the solar radiation in Latvia, the practise has shown that during summer time it can be purposeful to use the solar incidence for production of electricity and domestic water heating, using solar panels or collectors. The amount of the produced heat or electric energy is higher, when the solar incidence is striking the face surface of the receiver, in our case solar panels, perpendicularly. For that, fixed or tracking the sun stands are used. The output of energy is higher, if panels are operating on tracking the sun stands, insuring the panels' face surface orientation perpendicular to the sunbeams all day round. For that, solar sensors and tracking mechanisms are used. They are the most important elements that determine safe and accurate operation of the system. The industry produces solar panels tracking stands turning the panels in zenith and azimuths plane around two axis simultaneously using two electric motors, which make the construction more complicated. Continuing the development of the single-engine twin drive systems, there was created a construction of the solar tracking stand having only one electric motor.Such construction has a more simple orientation mechanism and a cheaper solar sensor, using infrared diodes. Three different models of solar sensors were investigated, using different types and numbers of diodes. In the first model two infrared diodes are used, making the angle of solar radiation incidence $140^{\circ}$. In the second model four other types of diodes are used, making the angle of incidence $160^{\circ}$. In the third model 6 narrow-angle diodes are used, making the angle of incidence $130^{\circ}$. Experimental investigation is carried out for all three models.
\end{abstract}

Keywords: solar panels, stands, trackers, sensors.

\section{Introduction}

In practice, there are solar photovoltaic panels' systems used with fixed and tracking the sun stands. It has been proved that the efficiency of solar panels is higher, if the solar radiation strikes the panels working surface perpendicularly [1-3]. It means that the angle between the solar incidence and the panel surface normal, called the angle of incidence, is zero. In case the fixed stands are used, the panels, according to the geographic latitude of the place, are mounted so that the face surface is perpendicular to the sunbeams at noon. In order to get the maximum output from the operation of solar panels they have to be kept at the inclination to the solar radiation under the angle of incidence equal to zero all the time of operation. At selection the orientation and inclination of the panels the south facing zenith and azimuthal orientation have been applied. For that, usually special solar tracking stands, rotating the panels simultaneously in the zenith and azimuth planes, are used. They help increase the panel efficiency up to $50 \%$ [4;5]. The use of tracking the sun stands is advisable also in case, when the area for placing the panels is limited, like on the roofs and facades of houses or other structures. Latvia is located on the 57 degree of latitude and has long daily shining time, until 17 hours and 53 minutes in the middle of summer and making more than 268-degree pass. Fixed solar panel energy from the sun can be produced during 12 hours in the angle of incidence not more than 180 degrees. The rest of the incidence falls behind the panel's face surface.Our experimental investigation using themovable meteorological data-measuring device DMM-4 showed that in Latvia in 2005 from April till November the tracking the sun surface received by 1.39 times more solar radiation energy than in the south direction perpendicular to solar beams in noon fixed surface $[1 ; 6]$.During the years 2005-2007 from April until November tracking the sun surface on the average had received 1.40 times more solar energy than in the south direction perpendicular to solar beams in noon fixed surface [3]. This increase can be obtained in two ways, by the use of the solar tacking stand or enlarging the working surface of the panels. In both cases additional resources are required. Comparing both variants from the economic point of view, the advantage is for the cheapest system. Therefore, in order to use a tracking the sun stand, its construction has to be simple, with small exploitation expenses, enough precise and operationally safe. Tracking the sun solar panels in fact mean on the earth polar axis mounted solar panels rotation in the opposite to the earth rotation direction, with the speed equal to the earth rotation speed at the same moment. The direction of the earth polar axis in relation to the earth surface (horizon) depends on the latitude degree of the place. On the horizon it is parallel to the horizon, on the poles it is perpendicular the horizon, but in every place it is $90^{\circ}-\varphi$, where $\varphi$ is the 
latitude of the place [7;8].In order that during all the year round solar panels are oriented to the sun, that is, all the year the solar incidence is perpendicular to the panel's face surface, the change of the sun-earth declination angle and the velocity of the earth rotation have to be taken into consideration [9;10]. The correction of the zenith angle $\left( \pm 23.45^{\circ}\right)$ in accordancewith the changes of the declination angle, the correction of the azimuth angle $( \pm 15 \mathrm{~min})$ in accordance with the time equation [8] have to be done. In connection to this,depending on the panels orientation accuracy required, single axis or two axes solar tracking stands are used. In devices of two axes drive, two electric motors are used; in one axis devises one motor is used. Generally, in practise both variants stationary placed and tracking the sun solar panels are used. Tracking the sun makes the system more complicated and expensive. Therefore, detail economic calculation should be done for choosing the particular design.

\section{Materials and methods}

Many variations of tracking stands for automatic orientation of solar panels are in operation. There are trackers based on the clockwork principle and on the computer controlled incremental servo drives, which can operate in the dark, and the motion of the stands programmed for a long time of operation. There are trackers based on the principle of Freon evaporation and condensation, trackers based on the comparison principle of the differential amount of sunlight on sensor photovoltaic cells, and many others [5;6]. All they usually have some sort of a sensor and a tracking mechanism. The sensor (photoelectric transformer) gives commands to the tracking mechanism, turning the panels in the zenith, azimuth or both planes simultaneously. In order to manufacture solar sensors it is possible to use photo-resistors, phototransistors, photo diodes and other elements of electronics. In the frame of our further investigation two solar sensors of the same construction, but with different diodes are manufactured and used (Fig.1).

a)

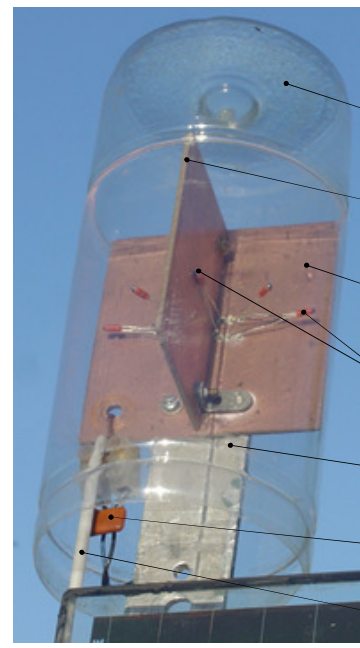

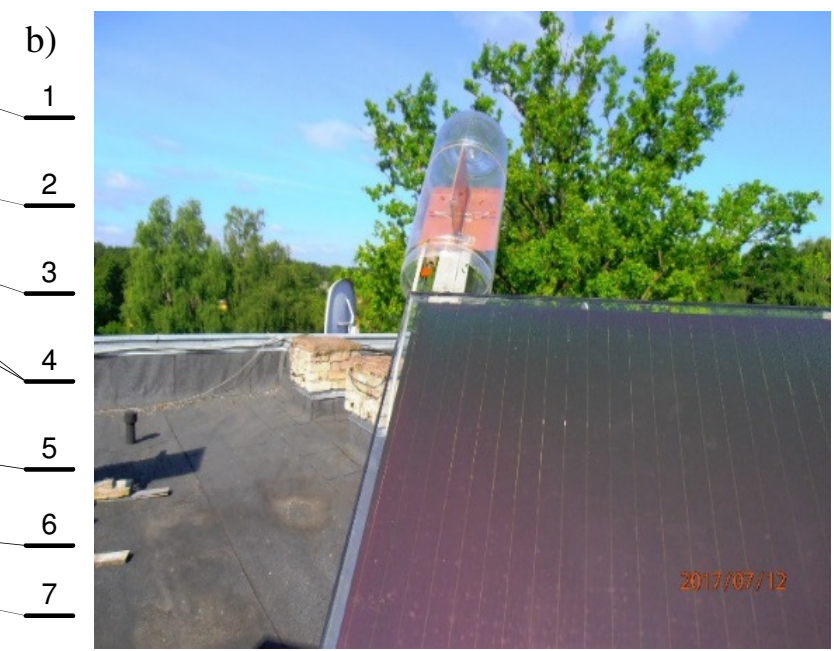

Fig. 1. Solar sensor with photo diodes construction of sensor (a), solar sensor fixed to solar panel placed on roof of house (b): 1 - transparent cover; 2 - parting plate; 3 - base plate; 4 -infrared radiation diodes; 5 -mounting plate; 6 - fault blocking capacitor $(0.5 \mu \mathrm{F}) ; 7$ - current output

The device (Fig. 1a) consists of a mounting plate 5, on which a base plate 3 with a parting plate 2 are fixed. The parting plate 2 divides the face surface of the base plate 3 in the east and west parts. On each side of the parting plate 2 and on the base plate 3 the experimental infrared diodes 4 are placed. There are a fault blocking capacitor $(0.5 \mu \mathrm{F}) 6$ and a current output contact 7 fixed to the base plate 5 . A transparent glass sheath 1 covers the construction, protecting it from moisture. The developed solar sensor is fixed to the face surface of the solar panel, placed on the sun-tracking stand on the roof of a house (Fig.1b).

Our previous experimental investigation [2] has shown that in wet mornings and after rain the sensors become covered with dew and start to work only when get dry, what takes hours. For starting the work of the stand, the sensor have to produce voltage not less than $0.1 \mathrm{~V}$. Therefore, the aim of the work was to develop a photoelectric solar sensor with a wide enough angle of the perception of the solar radiation incidence, which would be able after rain and in the mornings quickly renew the work 
ability of the solar stand. In order to record the characteristic curves of the diodes, a special devise was created and used (Fig. 2).

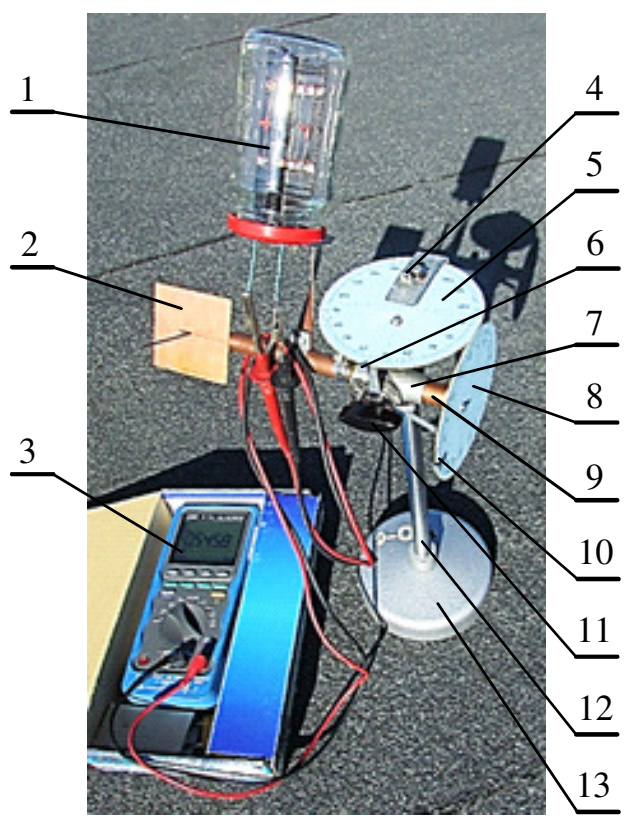

Fig. 2. Devise for recording characteristic curves: 1 - research sensor; 2 - sunbeam flow direction indicator; 3 - multi-meter FINEST 707; 4 - location of other research devises; 5 - disk at the end of the vertical axis 9 (fixed to the axle) with azimuth turning angle measurement (2-degree sections);

6 - horizontal axis disc section index; 7 - shaft with bearings; 8 - disk with tilt angle in zenith;

9 - horizontal spindle for installation of research devises; 10 - vertical axis disc section index; 11 - horizontal shaft lock;12 - vertical axis; 13 - base

The characteristic curves were obtained as follows. The probe with the bracket is fixed to the horizontal axis 9 (Fig.2) of the device, which is fixed rigidly with respect to the shaft 7 with the fixing screw 11 of the horizontal axis, so that the sensor does not rotate arbitrarily in the plane of the zenith. The other side of the sensor is the same as 11.The vertical axis fixing bolt in Fig. 2 is not visible. When both screws are screwed, nothing can be swiveled, when the screw is removed - the sensor is freely rotatable and fixed with the mentioned screws in the azimuth and zenith angles.

When starting work, unscrew the bolt fixing the vertical axis and turn the horizontal spindle 9 in the azimuth plane until the pointer 6 is on the zero scale of the disc 5 . Then lock it in this position fixed by the vertical axis-fixing bolt. Holding the base 13 and rotating the base, orient the sensor to the sun on the azimuth and zenith (using $2 ; 9 ; 11$ ). We connect the sensor current output circuit to the multi-meter (scale $\mathrm{mV}$ ). We turn on the multi-meter and by repeatedly changing the stand behind the base 13 , we reach the multi-meter 0 in the azimuth plane. Unscrew the bolt fixing the vertical axis and by holding the end of the spindle 9 , turn the sensor to one side, such as the east, no more than $180^{\circ}$ until the multi-meter reading becomes 0 .

The sensor curve is obtained by rotating the sensor back to the west with a certain step, such as $10^{\circ}$, and the multi-meter reading is recorded for each step. The sensor voltage is a function of the sensor angle of rotation. By processing the resulting data table in Excel, we obtain a graphical representation of the sensor curve, for example, Fig. 5. In order to obtain the characteristic curves of the diodes, the place 4 (Fig. 2) is used, on which the base with the diode-mounting contact socket was fixed.For the experimentally obtained result recording data Logger HOBO-H08-007-02 was used; the voltage was measured using the multi-meter FINEST 707with accuracy $0.1 \%+2$. For the data processing the computer program Excel was used.

\section{Results and discussion}

On the base of infrared diodes, three solar tracker sensor models were created and investigated. The models differ in the type and number of the diodes used. In the first model, twowide-angle $\left(140^{\circ}\right)$ 
infrared radiation diodesHPDR3K are placed on each side of the parting plate, making the angle of incidence(the angle of light perception) $\pm 140^{\circ}$, which is enough that the solar stand is working perfectly during the longest summer days. The diodes referring to the parting plate are placed under the angle $30^{\circ}$ (Fig.3).In order to minimise the reflection of the sunbeams, the surface of the plates is covered with tarnish silicone colour.

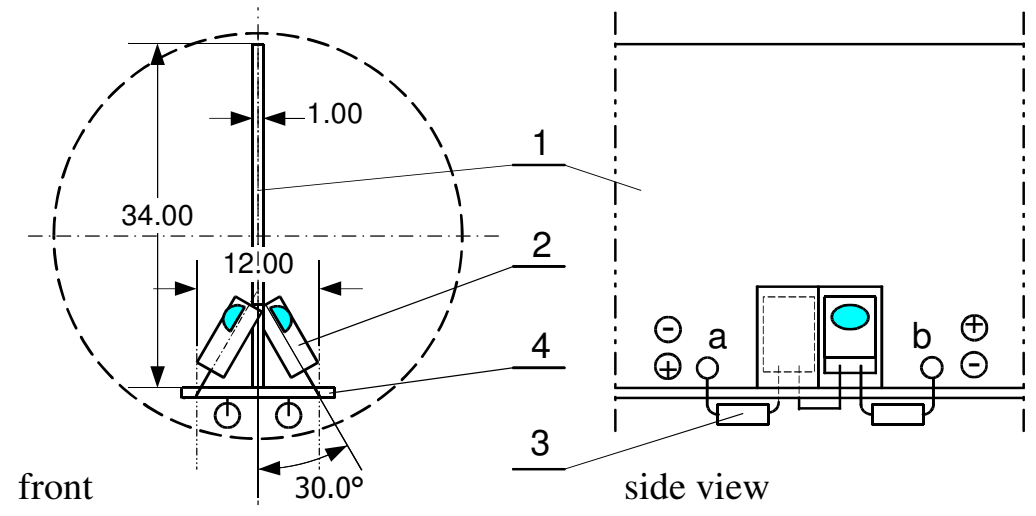

Fig. 3. Design of solar sensor with two infrared radiation diodes HPDR3K placed on each side of parting plate: 1 - parting plate; 2 -infrared diodes HPDR3K; 3 - electric resistances; 4 - mounting plate; $\mathrm{a} ; \mathrm{b}$ - current output

Recorded characteristic curves of the sensors with the corresponding diodes are given in Fig. 4. From Fig. $4 \mathrm{a}$ it follows that at the intensity of solar radiation $P s \approx 780 \mathrm{~W} \cdot \mathrm{m}^{-2}$ and loud resistance $R=0.4 \mathrm{k} \Omega$, the diodes HPDR3Kproduce maximum power $0.25 \mathrm{~mW}$, but the diodes $\mathrm{KP}-3216 \mathrm{~F} 3 \mathrm{C}$ at the intensity of solar radiation $P s \approx 680 \mathrm{~W} \cdot \mathrm{m}^{-2}$ and loud resistance $3 \mathrm{M} \Omega$ produced maximum power is $0.105 \mathrm{~mW}$. At decreased loud resistance up to $3.9 \mathrm{k} \Omega$, the produced power of the diodes HPDR3K increases until $0.067 \mathrm{~mW}$, but the voltage decreases until $519 \mathrm{mV}$.

a)

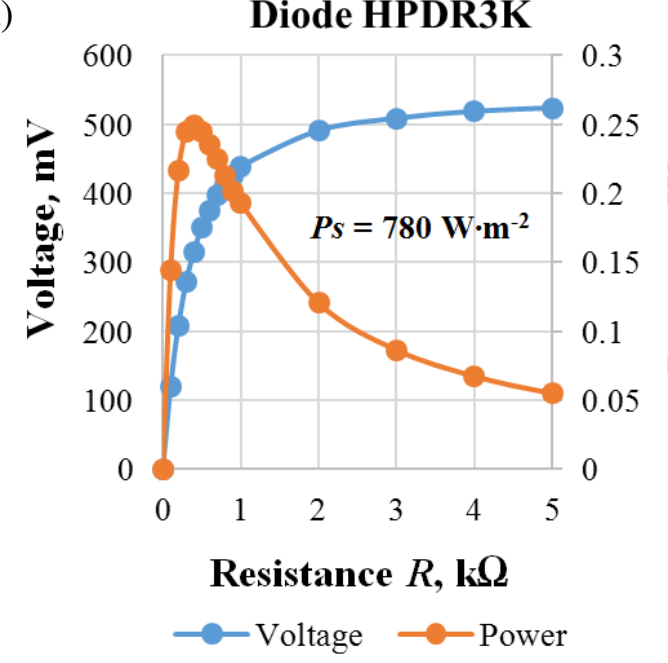

b)

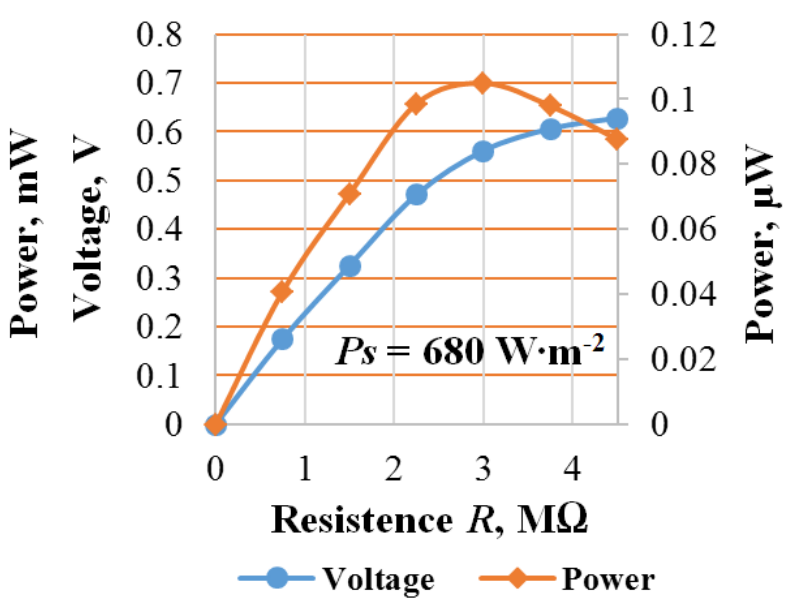

Fig. 4. Characteristic curves of sensors with corresponding diodes: $P s$ - intensity of solar radiation; $R$ - loud resistance

In the second model of the solar sensor four diodes KP-3216F3C were used, two on each side of the parting plate. One of the diodes with its face surface parallel to the parting plate, another perpendicular to the parting plate. The sensor at the loud resistance $3 \mathrm{M} \Omega$ and intensity of solar radiation $P s \approx 680 \mathrm{~W} \cdot \mathrm{m}^{-2}$ had produced the voltage $560 \mathrm{mV}$ (Fig. $4 \mathrm{~b}$ ). In parallel to both diodes, an electric resistor 3 was connected (Fig. 3). It has been noticed that the produced sensors are envisaged for working with operational amplifiers, which have high resistance of the external circuit. It gives a possibility for the sensors to use diodes of low power. Using the device (Fig. 2), characteristic curves of both types of solar sensors have been obtained. In Fig. 5 the characteristic curves of solar sensors 
with two wide $\left(140^{\circ}\right)$ angle diodes HPDR3K (a) and with four $120^{\circ}$ angle diodesKP3216F3C (b) are presented.

a)

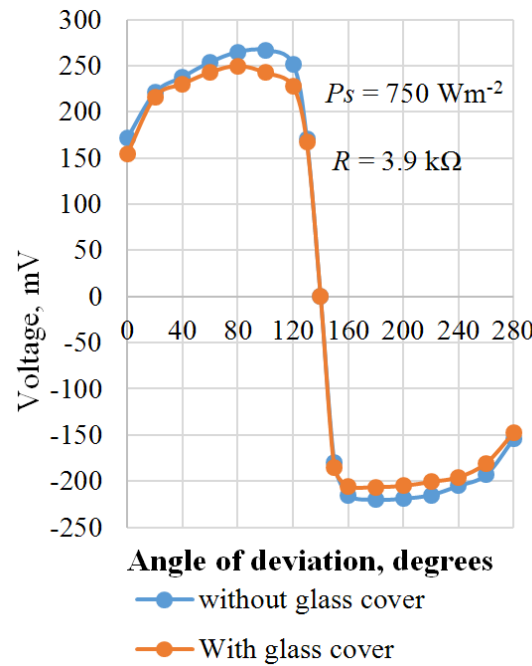

b)

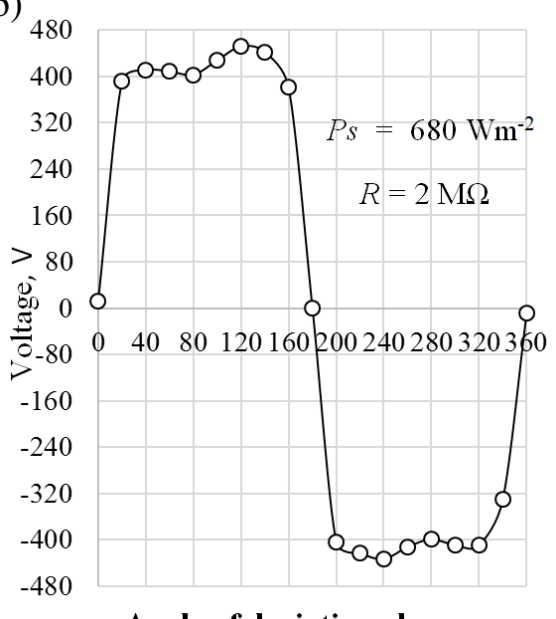

Fig. 5. Characteristic curves of solar sensor with two diodes HPDR3K (a) and with four diodes KP3216F3C (b): $P s$ - intensity of solar radiation; $R$ - loud resistance

The voltage on the sensor clamps is given, depending on the angle of deviation of the solar radiation from the normal of the solar panel surface.

In the third version of the solar sensor for the solar tracking stand six narrow-angle photo diodes were used [2]. The characteristic curve of the sensor, obtained using the devise (Fig. 2), is presented in Fig. 6.

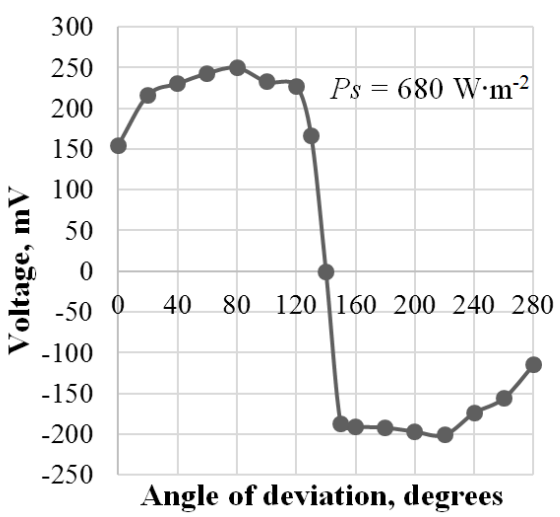

Fig. 6. Characteristic curves of solar sensor with six narrow angle diodes:

$P s$ - intensity of solar radiation

The sensor characteristic curves indicate the value of the voltage produced by the sensors, depending on the angle of deviation of solar radiation from the normal of the panel surface.

Comparing the curves given in Fig. 5 and Fig. 6, it can be seen that they are similar and show that the necessary calculated angle of solar incidence about $130^{\circ}$ is ensured. The sensor with narrow angle diodes had worked perfectly, but after manufacturing of the sensor, the diodes position has to be regulated, because the maximum of theirperception ability does not coincide with the diodes axis of symmetry. That makes the construction less convenient at exploitation.

\section{Conclusions}

For development of the sensor for the single-engine two-axle solar panels tracking the sun stand the principle of the solar radiation direction was applied.

The construction with a parting plate for the use of infrared radiation diodes and the devise for recoding the characteristic curves of solar sensors have been developed and used. 
Using two vide angle solar radiation diodes of HPDR3K type, placing them one on each side of the parting plate, or solar radiation diodes of KP3216F3C type, placing two on each side of the parting plate, allows to create a small, simple, and inexpensive solar sensor with a solar capture angle of up to $\pm 180^{\circ}$.

In case of the use of narrow angle diodes $\left( \pm 130^{\circ}\right)$, their number should increase to six, it makes the design more complex and there is a need to adjust the curve after the sensor has been made.

\section{References}

[1] Putans H., Ziemelis I., Putans A., Ziemelis E. Movable device for measuring and registration of meteorological parameters. Proceedings of the International Scientific Conference "Engineering for Rural Development”, Jelgava, Latvia, 2005, pp.222-227.

[2] Putans H., Ziemelis I., Pelece I., Snegovs A. Solar tracking stand for solar panels and collectors. Proceedings of the International Scientific Conference "Engineering for Rural Development", Latvia University of Life Sciences and Technologies, Jelgava, Latvia, 2018, pp.1734-1739.

[3] Rivza P. Atjaunojamā enerǵija un tās efektīva izmantošana Latvijā (Renewable energy and its effective use in Latvia). Monograph, Jelgava, Latvia, 2012, p.391. (In Latvian).

[4] Pouser Felix A., Karl-Heinz Remmers, Schnauss. Solar Thermal Systems. Solarpraxis, Berlin, 2002, p.364.

[5] Paulek V., Libra M. Photovoltaic. Prague, 2010, p.169.

[6] Dual-axis solar tracker for 4 panels, ST44M2V4P. [Online] [07.04.2018]. Available at: http://www.solar-motors.com

[7] Galins A., Laizans A., Kancevica L. Alternatīivās energèetikas iekārtas (Alternative energy devices). Jelgava, Latvia, 2008, p.316. (In Latvian).

[8] Харкнесс Е., Мехта М. Регулирование солнечной радиации в зданиях (Regulation of solar radiation in premises), Москва, Стройиздат, 1984, 177 стр. (In Russian).

[9] Харченко Н.В. Индивидуальные солнечные установки (Individual solar appliances). М. Энергоиздат, 1991, 208 c. (In Russian).

[10] Duffie Johan A., Beckman A., William A. Solar Engineering of Thermal Processes, 2006, p. 908. 